\title{
P01-035 - Long-term IV colchicine in oral colchicines failure
}

\author{
O Feld ${ }^{1}$, I Ben Zvi ${ }^{1}$, OL Kukuy ${ }^{2}$, A Livneh ${ }^{3,4^{*}}$ \\ From 7th Congress of International Society of Systemic Auto-Inflammatory Diseases (ISSAID) \\ Lausanne, Switerland. 22-26 May 2013
}

\section{Introduction}

Various levels of oral colchicine resistance is still an unmet challenge of FMF treatment. IV colchicine was shown to be effective and safe answer, but its long term outcomes are not known.

\section{Objectives}

To determine long term effectiveness and safety of IV colchicine treatment in oral colchicine refractory or intolarant FMF patients.

\section{Methods}

Included were all patients, experiencing $\geq 1$ attack per month, or intolerant to adequate dose of oral colchicin, for which they receive IV colchicine (pharmacy preparation under government control) for at least 1 year. Retrieval of data was based on patient interviews, files and a detailed questionnaire, focusing on clinical, demographic and genetic data. Effect of colchicine was determined, by computing attack rate, duration and intensity, the later with $1-10$ scale.

\section{Results}

Ten of 11 identified patients, on long term IV colchicine treatment, consented to partake. Treatment lasted $3.6 \pm 2.7$ (1- 10) years. More than $50 \%$ reduction in the rate of abdominal, chest, joint and skin attacks was noted by 8 of 10 patients. The intensity of the attacks dropped by a mean of $50 \pm 22 \%$ and the duration by $40 \pm 20 \%$. In 4 patients the favorable effect has decreased partially, but in only one treatment was stopped for this reason. Treatment was terminated in another 2 for loss of venous access (1) and for paresthesis. Adverse effects included diarrhea
(1 patient), vomiting (2), injection site pain (3), headache (1), muscle pain (1), injection site phlebitis (1) and arm paresthesis (1).

\section{Conclusion}

Long term parenteral colchicine treatment proved effective and safe. Downloading I.V. colchicine off the shelves due to intoxication associated with uncontrolled and unjustified use for back pain, had serious negative impact on our armamentarium for oral colchicine nonresponsiveness and intolerance.

\section{Disclosure of interest}

None declared.

\section{Authors' details}

${ }^{1}$ Medicine F, SHEBA MEDICAL CENTER, Rammat Gan, Israel. ${ }^{2}$ Nephrology and Hypertension Institute, SHEBA MEDICAL CENTER, Rammat Gan, Israel.

${ }^{3}$ Sackler Faculty of Medicine, Tel Aviv University, Tel Aviv, Israel.

${ }^{4}$ Heller Institute for Medical Research, SHEBA MEDICAL CENTER, Rammat Gan, Israel.

Published: 8 November 2013

doi:10.1186/1546-0096-11-S1-A39

Cite this article as: Feld et al:: P01-035 - Long-term IV colchicine in oral colchicines failure. Pediatric Rheumatology 2013 11(Suppl 1):A39.

${ }^{3}$ Sackler Faculty of Medicine, Tel Aviv University, Tel Aviv, Israel

Full list of author information is available at the end of the article

(c) 2013 Feld et al; licensee BioMed Central Ltd. This is an Open Access article distributed under the terms of the Creative Commons 